\title{
Tropical Splenomegaly Syndrome in a Rwandan Kindred in Uganda
}

\author{
JOHN L. ZIEGLER， PIETER C. STUIVER
}

British Medical fournal, 1972, 3, 79-82

\section{Summary}

Twenty members of an immigrant Rwandan kindred were all found to have tropical splenomegaly syndrome compared with 29 out of $\mathbf{5 0}$ matched neighbour controls. Splenomegaly among the controls tended to cluster within families. IgM levels were significantly raised in the kindred compared with the control subjects without splenomegaly but were similar to those of neighbours with splenic enlargement. We advance a hypothesis that tropical splenomegaly syndrome results from the production of circulating immune complexes in individuals genetically predisposed to produce an IgM antibody response.

\section{Introduction}

The aetiology of tropical splenomegaly syndrome is unknown, but there is evidence, mostly indirect, implicating an abnormal immunological response to malaria (Gebbie et al., 1964; Hamilton et al., 1965, 1969; Marsden et al., 1967; Pitney, 1968; Watson-Williams and Allan, 1968; Shaper, 1969; Sagoe, 1970; Stuiver et al., 1971). Epidemiological studies in Uganda and New Guinea have suggested tribal factors in the aetiology, but further support of a genetic predisposition is lacking (Hamilton et al., 1965; Pryor, 1967; Shaper, 1969).

In September 1967 we studied an immigrant Rwandan patient with tropical splenomegaly syndrome who had lived in the Mengo district of Uganda all her life. She reported that many members of her family also suffered from a similar condition, and we managed to find 20 relatives, all of whom had splenomegaly. We report here our clinical, immunological, and epidemiological studies of these people over a period of three years. We also report the results of our ascertainment of the presence of splenomegaly among 50 of their nearest neighbours matched for age, sex, and tribe.

\section{Persons Studied}

\section{THE PATIENT}

The patient, a 12-year-old Rwandan girl of the Tutsi tribe, was admitted to Mulago Hospital, Kampala, on 9 September 1967 with a large mass in the abdomen which had been causing discomfort since childhood. She had also had intermittent fevers and cough. A diagnosis of tropical splenomegaly syndrome was made and she was transferred to the Lymphoma Treatment Centre for special investigation.

The girl was anaemic and thin, and had a soft holosystolic murmur in the mitral area radiating to the axilla. The spleen was enlarged $22 \mathrm{~cm}$ below the left costal mangin and the liver $4 \mathrm{~cm}$ below the right costal margin. The haemoglobin was $6.8 \mathrm{~g} / 100$ $\mathrm{ml}$ W.B.C. $3,500 / \mathrm{mm}^{3}$, platelets $80,000 / \mathrm{mm}^{3}$, and reticulocytes $4 \%$. Several blood films for malaria parasites were negative. The

\footnotetext{
Uganda Cancer Institute, Department of Surgery, Makerere University Medical School, Kampala, Uganda

JOHN L. ZIEGLER, M.D., Director

PIETER C. STUIVER, M.D., Lecturer in Medicine (Present address: Harbour Hospital, Rotterdam, The Netherlands)
}

bone marrow showed reactive hyperplasia, liver function studies were normal, and a Coombs test was negative. A chest radiograph showed slight cardiomegaly, and an electrocardiogram showed flat to inverted $T$ waves in all leads. Liver biopsy showed moderate hepatic sinusoidal lymphocytosis with Kupffer cell hyperplasia and absence of malarial pigment, findings consistent with a diagnosis of tropical splenomegaly syndrome.

After splenectomy on 23 October and postoperative pneumonia the patient made a satisfactory recovery and was discharged. When seen in April 1968 she was well but the liver was enlarged 10 $\mathrm{cm}$ below the right costal margin. The haemoglobin was 12.6 $\mathrm{g} / 100 \mathrm{ml}$, W.B.C. $23,000 / \mathrm{mm}^{3}$, and the platelets $315,000 / \mathrm{mm}^{3}$. A liver biopsy showed pronounced hepatic sinusoidal lymphocytosis. She was given chloroquine phosphate $500 \mathrm{mg}$ weekly. The liver completely regressed in size within four months, and a follow-up liver biopsy showed only minimal hepatic sinusoidal lymphocytosis. The cardiac abnormalities persisted, but when last seen she was well and asymptomatic.

\section{PATIENT'S KINDRED}

The patient reponted that her two siblings, her father, and her paternal grandfather also suffered from "akabengo," the local name for splenomegaly. Her pedigree is shown in Fig. 1, in which she is IV 7.

Twenty relatives encompassing three generations were traced and examined. All had splenomegaly, and 17 were admitted to hospital for further investigation. All the relatives lived within a 10 -mile $(16 \mathrm{~km})$ radius in Bulemezi County, East Mengo distriot.

The patient was the only one of the family who had massive splenomegaly. The remainder had mild to moderate splenic en-

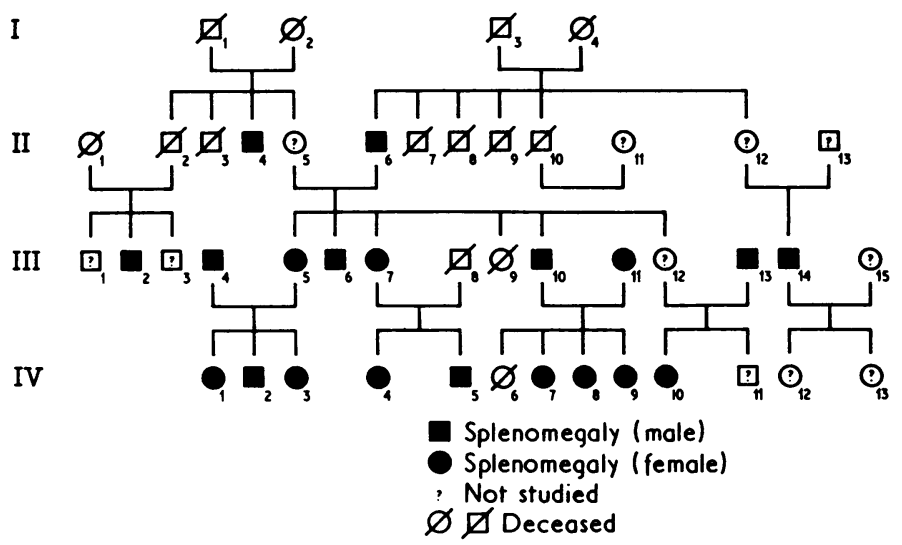

FIG. 1-Pedigree showing splenomegaly in a Rwandan kindred (patient is IV 7.)

TABLE I-Clinical Features of 20 Patients with Splenomegaly

\begin{tabular}{|c|c|c|c|c|}
\hline Generation & No. & $\underset{\text { (Range) }}{\text { Median Age }}$ & $\begin{array}{c}\text { Median Spleen Size } \\
\text { (cm) (Range) }\end{array}$ & $\begin{array}{l}\text { No. with } \\
\text { Symptoms }\end{array}$ \\
\hline $\begin{array}{l}\text { II-III } \\
\text { IV }\end{array}$ & 11 & $\begin{array}{l}38(30-60) \\
11(8-25)\end{array}$ & $\begin{array}{r}10(3-12) \\
8(4-22)\end{array}$ & $\begin{array}{l}5 \\
3\end{array}$ \\
\hline
\end{tabular}

largement (Table 1). Only eight complained of pain or discomfort in the left upper quadrant. Five of these were in generation III, and they had had abdominal discomfort since ohildhood. They tended to have the largest spleens, and "therapeutic" scarification of the skin overlying the spleen was noted. Slight degrees of hepatic enlargement $(2-5 \mathrm{~cm}$ below the right costal margin) were found in all subjects. 


\section{Results of Investigations}

The 17 relatives admitted to hospital had only mild anaemia, slightly more pronounced in generation IV, and normal W.B.C and platelet counts (Table II). Differential W.B.C. counts were within the normal range for Uganda (Shaper and Lewis, 1971)

TABLE II-Haematological Values in 17 Patients with Splenomegaly

\begin{tabular}{|c|c|c|c|c|}
\hline Generation & No. & $\begin{array}{c}\text { Median } \\
\text { Haemoglobin } \\
\text { (Range) }(\mathbf{g} / 100 \mathrm{ml})\end{array}$ & $\begin{array}{c}\text { Median W.B.C. } \\
(\text { Range }) \\
\left(\times 1,000 / \mathbf{m m}^{3}\right)\end{array}$ & $\begin{array}{c}\text { Median Platelets } \\
(\text { Range }) \\
\left(\times 1,000 / \mathrm{mm}^{3}\right)\end{array}$ \\
\hline $\begin{array}{ll}\text { II-III } & .\end{array}$ & $\begin{array}{l}9 \\
8\end{array}$ & $\begin{array}{l}11 \cdot 1(9 \cdot 6-12 \cdot 0) \\
10 \cdot 5(6 \cdot 4-12 \cdot 4)\end{array}$ & $\begin{array}{l}6 \cdot 9(4 \cdot 0-11 \cdot 4) \\
7 \cdot 3(4 \cdot 3-8 \cdot 9)\end{array}$ & $\begin{array}{c}200(150-440) \\
210(80-410)\end{array}$ \\
\hline
\end{tabular}

and reticulocyte counts ranged from 0.5 to $8 \%$, with a median of $2.5 \%$. Blood films were positive for Plasmodium falciparum in only 5 out of 16 patients. No patient had glucose-6-phosphate dehydrogenase deficiency, and all had haemoglobin AA genotype. The Coombs test was negative in all patients. The blood groups were either type $\mathrm{O}$ or type $\mathrm{A}$ Rh-positive, with compatible distribution in appropriate family sub-groups. Bone marrow examination in seven patients showed only hyperplastic normoblastic erythropoiesis.

Urine analyses were normal. Stool examination showed a small number of hookworm ova in all specimens and Tatnia saginata ova in three. Examination of eight specimens with the Telemann acid-ether concentration technique failed to find ova of Schistosoma mansoni.

Studies of liver function were normal except in Patient IV 10, who had a slightly raised bilirubin level. This was attributed to haemolysis induced by acute falciparum malaria, and it subsided with treatment. Liver biopsies were normal in three patients and in 11 showed mild to moderate hepatic sinusoidal lymphocytosis with varying degrees of Kupffer cell hyperplasia. No evidence of portal, parenchymal, or biliary disease was observed. Imprint preparations and electron micrographs of two specimens with hepatic sinusoidal lymphocytosis confirmed the lymphocytic nature of the sinusoidal infiltrate, and the latter technique showed severely attenuated Kupffer cells with amorphous granular material in the cytoplasm (Fluck and Hutt, 1972). Serial liver biopsies in Patient III 2 after long-term ohloroquine prophylactic treatment showed a normal liver, whereas a pretreatment biopsy had shown moderate hepatic sinusoidal lymphocytosis.

Seventeen patients were examined for signs of endomyocardial fibrosis, a condition which commonly affects Rwandan immigrants (Shaper and Coles, 1965). In seven patients abnormal cardiac shadows of varying degrees were seen, and in six non-specific $\mathrm{T}$-wave abnormalities were noted. Five patients had regurgitant murmurs (three mitral, two mitral and tricuspid). None of them had symptoms of cardiac disease when first seen. One (III 2), however, returned after a year with a severe right-sided congestive cardiac failure associated with acute bronchitis. Four of these patients underwent cardiac catheterization with cineangiocardiograms. A diagnosis of endomyocardial fibrosis was established in three and was. suspected but not proved in the fourth (Patel et al., 1971). Liver biopsy in all four showed sinusoidal lymphocytosis and no evidence of centrolobular congestion.

\section{CLINICAL FOLLOW-UP}

Clinical follow-up of the kindred over the past three years has yielded several points of interest. In November 1968 six family members with the largest spleens entered a randomized trial of malarial prophylaxis versus placebo. At the end of the 16-month trial the spleens of the patients receiving prophylactic chloroquine were significantly smaller and their symptoms less compared with the controls (Stuiver et al., 1971). All those among the kindred with symptoms were then placed on chloroquine and a similar therapeutic benefit was observed.

One patient (III 14), a 37-year-old man, was a night-watchman in Kampala when he was first seen, and no splenomegaly was noted. Several months later he returned to Bulemezi to tend cattle, and after three months his spleen was enlarged to $5 \mathrm{~cm}$ below the left costal margin. A haemogram was normal, a malarial film was positive for $P$. falciparum, and a liver biopsy showed hepatic sinusoidal lymphocytosis, Kupffer cell hyperplasia, and absence of malarial pigment. After three months' treatment with chloroquine phosphate, $500 \mathrm{mg}$ weekly, the spleen was no longer palpable.

During the follow-up period several intercurrent illnesses were noted. Nine patients were admitted with acute bronchitis. Four of them had several recurrences, and three were found to have active pulmonary tuberculosis. Five patients were plagued with recurrent staphylococcal pyoderma, and one patient suffered two episodes of staphylococcal pyomyositis. Three patients complained of intermittent arthralgia, often accompanied by fever, but acute episodes were not observed. No patient developed any lymphoproliferative disorder. Eight patients who were still on long-term chloroquine prophylaxis reported no symptoms and felt perfectly healthy.

\section{Immunological Studies}

Immediate and delayed cutaneous hypersensitivity responses to various intradermal antigens are summarized in Table III. Nine out of 14 patients were reactive to tuberculin, and three of them

TABLE III-Results of Skin Testing

\begin{tabular}{cc|c|c}
\hline Skin Test & & No. Tested & No. Positive \\
\hline Intermediate strength P.P.D. & $\ldots$ & 14 & $9^{*}(64 \%)$ \\
Brucellergen $\ldots$ & $\ldots$ & $7^{*}(54 \%)$ \\
Melcher schistosome antigen $\ldots$ & $\ldots$ & 13 & $5+(50 \%)$ \\
\hline
\end{tabular}

*Induration of $5 \mathrm{~mm}$ diameter at 48 hours.

tInduration of area of at least $1 \mathrm{~cm}^{2}$ and twice the control area at 15 minutes.

were found to have active pulmonary tuberculosis. Seven out of 13 patients were reactive to Brucellergen, but in none was the brucella agglutinin titre raised. Testing with schistosome antigens in 10 patients gave five positive immediate reactions, noted only with the adult and not the cercarial antigen preparations. The stools of these subjects were free of scistosome ova, however, and liver biopsy showed no evidence of hepatic schistosomiasis.

IgM levels were significantly raised among kindred members compared with neighbours without splenomegaly and control subjects in hospital (Fig. 2), but were similar to those of neighbours with splenomegaly. Though patients with the largest spleens

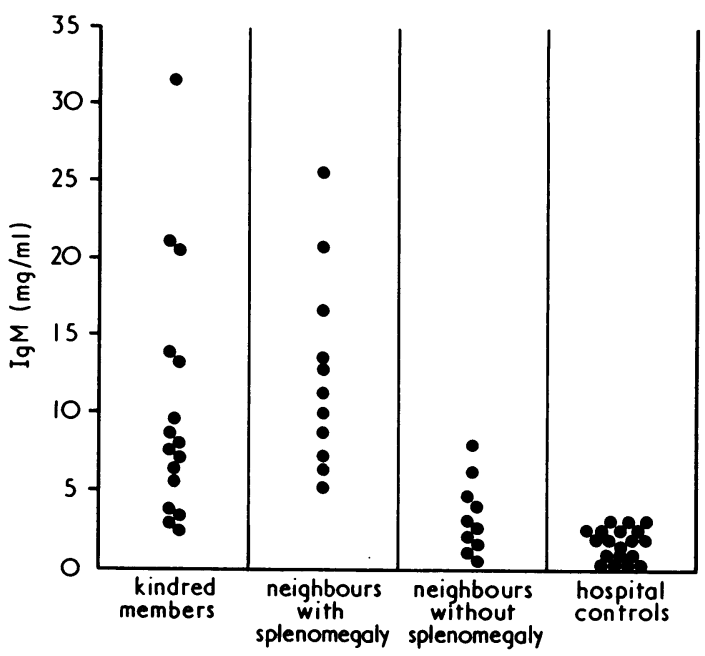

FIG. 2-IgM levels in kindred members and in neighbour and hospital controls. IgM levels in kindred members and neighbours with splenomegaly are similar but are significantly raised in comparison with those of neighbours without splenomegaly ( $P<0.01$ by Mann-Whitney $U$ test).

tended to have higher IgM levels, several patients with small or impalpable spleens had IgM levels well above the control range. IgM levels in patients on long-term treatment with chloroquine tended to decline slowly. No difference in IgG or IgA levels were detected between the kindred members and controls.

Complement (C3) levels in freshly obtained serum from various kindred members and neighbour controls were significantly lower among individuals with splenomegaly (all Rwandan adults residing in Bulemezi County) than in those without splenomegaly (Fig. 3). Four out of seven members of the kindred with tropical splenomegaly syndrome who were on malarial prophylaxis had C3 levels within the normal range, but three had hypocomplementaemia. 


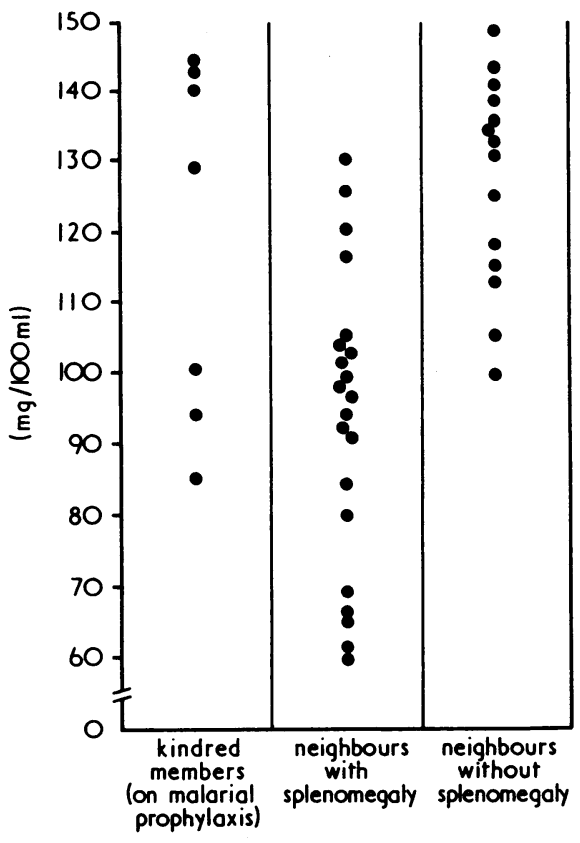

FIG. 3-Serum complement (C3) in kindred members and controls. A significant difference is noted between neighbours with splenomegaly and neighbours without splenomegaly ( $P<0.01$ by Mann-Whitney $U$ test).

All 18 sera available from family members were positive for rheumatoid factor, varying in titre from $1: 80$ to $1: 5,120$. There was no apparent correlation between the titres and the degree of splenomegaly, IgM levels, or complement level. Twelve sera were negative for typhoid and brucella agglutinins, and E.B. virus titres determined in 14 individuals were within the normal range (Henle et al., 1969).

\section{Epidemiology}

The grandfather (II 6) of the patient immigrated to the Mengo district, Uganda, with his six children around 1946. By 1950 all of the third generation had arrived in the district and all members of the fourth generation were born there. It borders on Lake Victoria and has an average annual rainfall of 50 in $(127 \mathrm{~cm})$. Malaria transmission is intensive throughout the year and the area is designated hyperendemic. The heads of the family groups are herdsmen and tend to change their residence often. The patient's family had lived in four different homesteads in Bulemezi County during the three years of observation.

There is remarkable uniformity in the living habits, diet, and socioeconomic status of the various family groups of the kindred

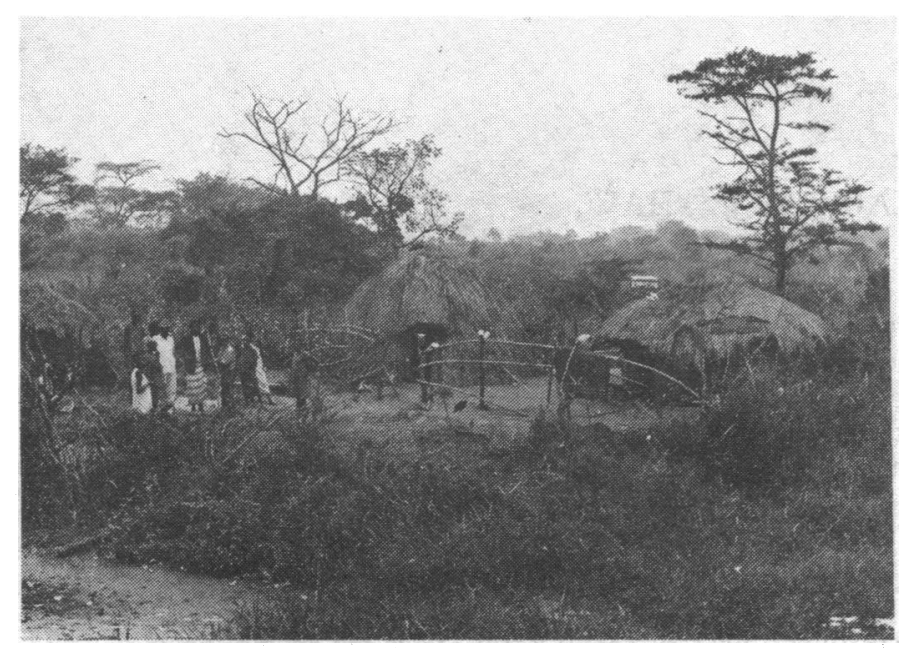

FIG. 4-Dwelling of the patient and her immediate family. The grassthatched huts are characteristic of all the dwellings of the kindred under study. under study. Each family group lives in a kraal, and at night all cattle, goats, and chickens are herded into the enclosure. Individual dwellings within the kraal are constructed of grass thatch and accommodate two to three people (Fig. 4). The diet consists of unboiled milk, cassava, matoke, and beans. Meat is eaten once a fortnight. Water for drinking is taken from a bore-hole located over a mile $(1.6 \mathrm{~km})$ from the kraal. Water for washing or watering cattle is obtained from a nearby swamp. The annual income of a family group is about 150 Uganda shillings and the socioeconomic status is just above the subsistence level.

\section{Controls}

In order to ascertain the prevalence of splenomegaly in the area in which the kindred lived $\mathbf{5 0}$ of the nearest neighbours matched for age, sex, and tribe were visited and examined. Though the Mengo district is populated predominantly by members of the Baganda tribe there are many scattered Rwandan immigrants, particularly in Bulemezi County. Thus it was not difficult to locate neighbour controls of the same tribe. Their living conditions and epidemiological features were identical to those of the kindred.

Splenomegaly of varying degrees was found in 29 of the neighbour controls (Table IV). This frequency is significantly lower

TABLE IV-Clinical Features of Neighbour Controls

\begin{tabular}{|c|c|c|c|c|c|c|}
\hline \multirow{2}{*}{$\begin{array}{c}\text { Age } \\
\text { (Years) }\end{array}$} & \multirow[t]{2}{*}{ No. } & \multicolumn{4}{|c|}{$\begin{array}{c}\text { Spleen Size } \\
\text { (cm below Costal Margin) }\end{array}$} & \multirow{2}{*}{$\begin{array}{l}\text { Total } \\
\text { Splenomegaly }\end{array}$} \\
\hline & & $\begin{array}{c}\text { Not } \\
\text { Palpable }\end{array}$ & $<2 \mathrm{~cm}$ & $2-5 \mathrm{~cm}$ & $>5-10 \mathrm{~cm}$ & \\
\hline $\begin{array}{l}<10 \\
10-19 \ldots \\
20-39 \ldots \\
\geqslant 40 \quad \ldots\end{array}$ & $\begin{array}{r}10 \\
9 \\
20 \\
11\end{array}$ & $\begin{array}{r}3 \\
2 \\
10 \\
6\end{array}$ & $\begin{array}{l}5 \\
4 \\
2 \\
1\end{array}$ & $\begin{array}{l}2 \\
2 \\
2 \\
2\end{array}$ & $\begin{array}{l}1 \\
6 \\
2\end{array}$ & $\begin{array}{r}7(70 \%) \\
7(78 \%) \\
10(50 \%) \\
5(46 \%)\end{array}$ \\
\hline Total & 50 & & & & & $29(58 \%)$ \\
\hline
\end{tabular}

$\left(P<0.055 \chi^{2}\right.$ test) than that observed in the kindred. The highest frequency was found in the younger age groups, compatible with that associated with hyperendemic malaria (World Health Organization, 1963). Over $40 \%$ of adults were also affected, and over one-third of these had moderate to marked splenic enlargement.

Thirty-nine members of 12 neighbour families were among the subjects examined (range two to six members per family). Splenomegaly tended to cluster within these families, but the numbers were too small to be statistically significant. Nine adult members of two generations of a Baganda kindred living in Bulemezi County (near the family of III 4 and 5) were also visited and examined. The spleen was palpable in only one individual (spleen tip only).

\section{Discussion}

Tropical splenomegaly syndrome is a significant clinical problem in the tropics. The secondary clinical and haematological effects of hypersplenism have been well described, but the pathogenesis of the underlying disorder is poorly understood. Malaria has been implicated, and the most convincing evidence is the amelioration of splenomegaly after prolonged malarial prophylaxis, but one of the perplexing questions is why only a small proportion of individuals exposed to malaria develop tropical splenomegaly syndrome.

The presence of the syndrome in all 20 members of a Rwandan kindred suggests a genetic predisposition.

The rise in IgM levels in the kindred was comparable to that in neighbour controls with splenomegaly but higher than in neighbours with no splenic enlargement. Studies of immunoglobulins in tropical splenomegaly syndrome have shown a marked reactive macroglobulinaemia, with exaggerated production of rheumatoid factor, autoantibodies, cold agglutinins, and cryoprotein (Wells, 1970). The reason for this gammopathy is obscure, and it may be related to an altered primary immune response or to a non-specific increase in globulin production resulting from hypertrophied reticuloendothelial tissues (Jandl et al., 1965). Since macroglobulinaemia is an almost constant 
feature of tropical splenomegaly syndrome there may be a genetic basis for this type of immune response (McDevitt and Benacerraf, 1969). There was a high prevalence $(58 \%)$ of splenomegaly among neighbour controls, which tended to cluster within families. The high frequency of splenomegaly among Rwandan immigrants is consistent with the observations of others (Hamilton et al., 1965; Shaper 1969). Nevertheless, the frequency $(100 \%)$ was significantly higher in the kindred than in the neighbour controls.

The possible relationship of tropical splenomegaly syndrome and endomyocardial fibrosis in the kindred is interesting in the light of the postulated autoimmune pathogenesis of endomyocardial fibrosis (van der Geld et al., 1966). Shaper et al. (1968) described an immunological syndrome largely affecting Rwandan immigrants consisting of raised IgM levels and raised malarial antibody titres in association with circulatory antibodies to IgG, heart, thyroid, and gastric parietal cells. They suggested that these are associated with an altered immunological response to malaria in subjects who may have an inherently unusual immunological constitution. The question of autoimmune disorders and malaria has been examined by others (Greenwood et al., 1971), and the problem is by no means settled.

The hypothesis that tropical splenomegaly syndrome is an "immune complex disease" receives support from several lines of evidence (Christian, 1969). The finding of low levels of serum complement among patients with the syndrome in the present study plus the finding of anticomplementary activity in sera of patients with tropical splenomegaly syndrome (Ziegler and Fife, unpublished) suggest in-vivo fixation of complement by antigen-antibody interaction. Cryoproteins observed in the sera of $84.6 \%$ of patients with tropical splenomegaly syndrome in New Guinea (Wells, 1970) most likely represent circulating immune complexes (Barnett et al., 1970).

Since patients with tropical splenomegaly syndrome have high titres of malarial antibody and live in regions of high malarial transmission, repeated and persistent antigenaemia is likely to occur. In the presence of antibody excess immune complexes will form. Because of the predominant IgM nature of the antimalarial antibody in patients with tropical splenomegaly syndrome (Mody, 1970) the circulating complexes will be large and produce continuous particulate stress to reticuloendothelial tissues. Such complexes might in themselves also be antigenic, including further antibody formation and macromolecular aggregation, thus perpetuating the disorder (Bonomo and Dammacco, 1971). Predisposition to the development of tropical splenomegaly syndrome may reside in the geneticallydetermined production of predominantly IgM antibody, as suggested in the present study.
Interruption of this postulated chain of events by the prevention of antigenaemia by prolonged malarial prophylaxis might explain the observed clinical amelioration and the return of IgM and complement levels towards normal after such treatment (Sagoe, 1970). Interruption of the immune response by immunosuppressive agents could also theoretically bring about clinical improvement, but it could not be recommended as specific therapy in view of the well-documented improvement on antimalarials.

We are indebted to the many clinicians and medical students who assisted in the clinical care of the patients reported here. Professors W. Parson and M. S. R. Hutt encouraged and supported the study. Miss P. Moriarty assisted with the schistosome antigen tests, and the antibody levels to E.B. virus were kindly measured by Dr. W. Henle, of Philadelphia, Pa., U.S.A. The study was supported by contract No. PH 43-67-1343 from the National Cancer Institute, Bethesda, Md.

\section{References}

Barnett, E. V., et al. (1970). Annals of Internal Medicine, 73, 95. Bonomo, L., and Dammacco, F. (1971). Clinical and Experimental Immuno$\log y, 9,175$.

Brown, I. N. (1969). Advances in Immunology, 11, 267.

Christian, C. L. (1969). New England fournal of Medicine, 280, 878.

Fluck, D., and Hutt, M. S. R. (1972). East African Medical fournal. In press. Gebbie, D. A. M., et al. (1964). Lancet, 2, 392.

Greenwood, B. M., Mulla, A. S., and Valkenburg, A. A. (1971). Clinical and Experimental Immunology, ,, 161 .

Hamilton, P. J. S., et al. (1965). East African Medical fournal, 42, 191.

Hamilton, P. J. S., et al. (1969). Lancet, 2, 109.

Henle, G., et al. (1969). Fournal of the National Cancer Institute, 43, 1147. Jandl, J. J., Files, N. M., Barnett, S. B., and MacDonald, R. A. (1965). Fournal of Experimental Medicine, 122, 299.

$\mathrm{McD}$ evitt, H. O., and Benacerraf, B. (1969). Advances in Immunology, 11, 31. Marsden, P. D., et al. (1967). Bulletin of the World Health Organization, 36, 901 .

Mody, N. J. (1970). M.D. Thesis, Makerere University, Kampala.

Patel, A. K., Ziegler, J. L., D'Arbela, P. G., and Somers, K. (1971). British Medical fournal, 4, 331 .

Pitney, W. R. (1968). Transactions of the Royal Society of Tropical Medicine and Hygiene, 62, 717.

Pryor, D. S. (1967). Quarterly fournal of Medicine, 36, 321.

Sagoe, A. (1970). British Medical fournal, 3, 378.

Shaper, A. G. (1969). Transactions of the Royal Society of Tropical Medicine and Hygiene, 63, 206.

Shaper, A. G., and Coles, R. M. (1965). British Heart Journal, 27, 121.

Shaper, A. G., Kaplan, M. H., Mody, N. J., and McIntyre, P. A. (1968). Lancet, 1, 1342.

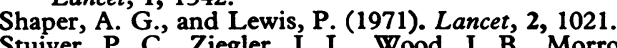
Stuiver, P. C., Ziegler, J. L., Wood, J. B., Morrow, R. H., and Hutt,
M. S. R. (1971). British Medical fournal, 1, 426.

van der Geld, H., Peetoom, F., Somers, K., and Kanyerezi, B. R. (1966). Lancet, 2, 1210.

Watson-Williams, E. J., and Allan, N. C. (1968). British Medical fournal, 4, 793 .

Wells, J. V. (1970). Transactions of the Royal Society of Tropical Medicine and Hygiene, 64, 531.

World Health Organization (1963). Terminology of Malaria and of Malaria Eradication, Geneva, W.H.O.

\section{$\mathbf{R}$ Factors in Hospital Infection}

\section{FELICITY M. ANDERSON, NAOMI DATTA, ELIZABETH J. SHAW}

British Medical fournal, 1972, 3, 82-85

\section{Summary}

In order to assess the clinical importance of $\mathbf{R}$ factors 524 "coliform" infections were studied in a general hospital.

\footnotetext{
Department of Bacteriology, Royal Postgraduate Medical School, London W.12

FELICITY M. ANDERSON, M.B., B.S., Registrar (Present address: Department of Bacteriology, West Middlesex Hospital, Isleworth, Middlesex)

NAOMI DATTA, M.D., M.R.C.PATH., Senior Lecturer

ELIZABETH J. SHAW, M.B., B.S., Research Fellow (Present address: Department of Bacteriology, St. Bartholomew's Hospital, London E.C.1)
}

Of these, 95 were caused by Pseudomonas aeruginosa. Among the remaining $429,43 \%$ were caused by drugresistant enterobacteria; resistance was frequently multiple and determined by transmissible $R$ factors. Choice of therapy was thus limited but in every case at least one antibiotic, effective in vitro, was still available.

\section{Introduction}

Hospital infections with Gram-negative bacilli have become more important in the past 25 years-that is, since the introduction of antibiotics (Finland, Jones, and Barnes, 1959). In the 